OPEN ACCESS

Edited by:

Alina Mihaela Mihai,

Beacon Hospital, Ireland

Reviewed by:

Vinay Sharma,

University of the Witwatersrand,

South Africa

Wenyin Shi,

Thomas Jefferson University,

United States

*Correspondence:

Huojun Zhang

chyyzhj@163.com

Specialty section:

This article was submitted to

Radiation Oncology,

a section of the journa

Frontiers in Oncology

Received: 11 July 2019 Accepted: 15 November 2019 Published: 10 December 2019

Citation:

Gu L, Qing S, Zhu X, Ju X, Cao Y, Jia Z, Shen $Y$, Cao F, Fang $F$ and Zhang H (2019) Stereotactic Radiation

Therapy (SRT) for Brain Metastases of Multiple Primary Tumors: A Single Institution Retrospective Analysis.

Front. Oncol. 9:1352.

doi: 10.3389/fonc.2019.01352

\section{Stereotactic Radiation Therapy (SRT) for Brain Metastases of Multiple Primary Tumors: A Single Institution Retrospective Analysis}

\author{
Lei Gu, Shuiwang Qing, Xiaofei Zhu, Xiaoping Ju, Yangsen Cao, Zhen Jia, Yuxin Shen, \\ Fei Cao, Fang Fang and Huojun Zhang*
}

Department of Radiation Oncology, Changhai Hospital Affiliated to Second Military Medical University, Shanghai, China

Purpose: To evaluate the efficiency and side effects of stereotactic radiation therapy (SRT) with or without other treatments for brain metastases (BM) from various primary tumors.

Methods: This was a retrospective analysis of 161 patients with brain metastases treated with SRT. Clinical data, EGFR mutation status and survival data were collected. Follow-up data was analyzed until December 2018. Kaplan-Meier and Cox proportional hazards regression analyses were used for the survival analysis.

Results: The median overall survival (OS) was 19 months. No difference was observed in OS between SRT group and SRT + whole brain radiation therapy (WBRT) groups $(p=0.717)$. Statistically significant factors of better OS after univariable analysis were no extracranial metastases $(p=0.016)$, BED $10-S R T \geq 50 G y(p=0.049)$, oligometastases (1-3 brain metastases) $(p<0.001)$, GPA score $\geq 2.5(p=0.003)$, RPA class I $(p=0.026)$, NSCLC tumor type $(p=0.006)$, targeted therapy $(p<0.001)$ and controlled extracranial disease $(p=0.011)$. Multivariate analysis indicated that higher BED $10-S R T(\geq 50 G y$, $\mathrm{HR}=0.504, p=0.027)$, controlled extracranial disease $(\mathrm{HR}=0.658, p=0.039)$ and targeted therapy $(H R=0.157,<0.001)$ were independent favorable predictors for OS. Besides that, we also find that the median overall survival (OS) was 22 months in NSCLC patients and controlled extracranial disease $(H R=0.512, p=0.012)$ and targeted therapy $(H R=0.168,<0.001)$ were independent favorable predictors for OS.

Conclusion: For patients with brain metastases, stable extracranial disease, higher $\mathrm{BED}_{10}-\mathrm{SRT}$ ( $\geq 50 \mathrm{~Gy}$ ) and targeted therapy may predict a favorable prognosis.

Keywords: stereotactic radiation therapy, brain metastasis, overall survival, prognostic factors, non-small-cell lung cancer

\section{INTRODUCTION}

Brain metastases are the most common intracranial malignancies, about $10-30 \%$ cancer patients develop brain metastases during the course of their diseases $(1,2)$ and 20 to $30 \%$ of patients with $\mathrm{BM}$ die as a result of poor local control (3). BM is one of the main causes seriously reduces the patients' life quality (4). Almost $40 \%$ patients will develop brain metastases during 
the course of their disease in non-small-cell lung cancer (NSCLC), and it may be even higher in those patients with epidermal growth factor receptor (EGFR) mutation $(4,5)$. Patients with EGFR-mutation may have a greater proportion of being diagnosed with brain metastases because of longer survival owing to targeted therapy and Central Nervous System (CNS) imaging technique improvement $(6,7)$.

There are various approaches for the treatments of brain metastases including surgical resection, stereotactic radiosurgery (SRS), whole brain radiation therapy (WBRT), systemic steroids and other combinations. Mintz et al. (8) demonstrated that surgery followed by WBRT obtained longer overall survival and better response to treatment compared to WBRT alone; but no differences were found in recurrence rate in metastasis site. Similar results were also published by Mintz et al. (8) Patchell et al. (9), and Vecht et al. (10).

In the RTOG 9508 trial (11), 333 patients with 1-3 brain metastases were randomly assigned to either WBRT or SRT-WBRT. WBRT and stereotactic boost treatment improved functional autonomy (KPS) for all patients and survival for patients with a single unresectable metastasis. In the secondary analysis performed after 10 years (12), 252 patients have been rearranged according to the GPA score. Survival advantage was found only in patients with higher GPA score (3.5-4) no matter the numbers of brain metastases.

\section{METHODS AND MATERIALS}

\section{Patient Selection}

From February 2012 to June 2017, 161 patients with single or multiple (up to 7) brain metastases with good performance status and synchronous/metachronous primary tumor were treated at the Radiation Therapy Department, Changhai Hospital, Naval Medical University. Follow-up data was analyzed until December 2018. The study was approved by the independent Ethics Committee of our hospital and all patients signed informed consents. Data necessary for analysis were extracted, compiled, and verified against patients' archived medical records. Data analyzed included primary cancer, karnofsky performance score (KPS), Graded Prognostic Assessment (GPA) score, recursive partitioning analysis (RPA) classification at the time of SRT, site of intracranial metastases, number of lesions treated, present of extracranial metastases, and date of death or last follow-up, SRT treatment records, WBRT treatment records, and status of primary disease and systemic disease at SRT.

Abbreviations: SRT, Stereotactic Radiation Therapy; BM, brain metastases; WBRT, whole brain radiation therapy; EGFR, epidermal growth factor receptor; NSCLC, non-small-cell lung cancer; SCLC, small-cell lung cancer; CNS, Central Nervous System; SRS, stereotactic radiosurgery; OS, overall survival; GPA, Graded Prognostic Assessment; RPA, recursive partitioning analysis; $\mathrm{BED}_{10}$-SRT, biological effective dose of SRT; KPS, karnofsky performance score; TKI, Tyrosine Kinase Inhibitor; QOL, quality of life.
TABLE 1 | Patients characteristics.

\begin{tabular}{|c|c|c|}
\hline Characteristics & $\begin{array}{l}\text { No./median } \\
\text { (range) }\end{array}$ & $\begin{array}{c}\text { Proportion } \\
(\%)\end{array}$ \\
\hline \multicolumn{3}{|l|}{ Sex } \\
\hline Male & 103 & 64 \\
\hline Female & 58 & 36 \\
\hline Age (y) & $61(33-87)$ & \\
\hline \multicolumn{3}{|l|}{ KPS } \\
\hline$\leq 70$ & 90 & 55.9 \\
\hline$>70$ & 71 & 44.1 \\
\hline \multicolumn{3}{|l|}{ Histology } \\
\hline NSCLC & 105 & 65.2 \\
\hline SCLC & 11 & 6.8 \\
\hline Breast & 7 & 4.3 \\
\hline Renal & 3 & 1.9 \\
\hline Gastrointestinal & 19 & 11.8 \\
\hline Others & 16 & 10.0 \\
\hline \multicolumn{3}{|l|}{ Primary tumor } \\
\hline NSCLC & 105 & 65.2 \\
\hline None NSCLC & 56 & 34.8 \\
\hline \multicolumn{3}{|l|}{ Synchronous BM } \\
\hline YES & 53 & 32.9 \\
\hline NO & 108 & 67.1 \\
\hline \multicolumn{3}{|l|}{ Extracranial metastases } \\
\hline YES & 91 & 56.5 \\
\hline $\mathrm{NO}$ & 70 & 43.5 \\
\hline \multicolumn{3}{|l|}{ Number of treated lesions } \\
\hline 1 & 99 & 61.5 \\
\hline 2 & 31 & 19.3 \\
\hline 3 & 11 & 6.8 \\
\hline 4 & 8 & 5.0 \\
\hline 5 & 2 & 1.2 \\
\hline$>5$ & 10 & 6.2 \\
\hline Time from diagnosis to brain metastasis (M) & $10(0-300)$ & \\
\hline System therapy cancer ${ }^{\star}$ & 93 & 57.8 \\
\hline \multicolumn{3}{|l|}{ Total BM volume } \\
\hline Per patient (cc) & $8.79(0.113-179.31)$ & \\
\hline Prescription dose & $27(20-40)$ & \\
\hline Fraction & $5(3-6)$ & \\
\hline $\mathrm{BED}_{10}$ & $38.016(16.6-84.375)$ & \\
\hline Fraction & $5(3-10)$ & \\
\hline SRT alone & 99 & 61.5 \\
\hline SRT+WBRT & 62 & 38.5 \\
\hline \multicolumn{3}{|l|}{ Controlled of primary tumor } \\
\hline Controlled & 92 & 57.1 \\
\hline Uncontrolled & 69 & 42.9 \\
\hline \multicolumn{3}{|l|}{ GPA score } \\
\hline 0.5 & 9 & 5.6 \\
\hline 1.0 & 22 & 13.7 \\
\hline 1.5 & 40 & 24.9 \\
\hline 2.0 & 30 & 18.6 \\
\hline 2.5 & 30 & 18.6 \\
\hline 3.0 & 20 & 12.4 \\
\hline
\end{tabular}


TABLE 1 | Continued

\begin{tabular}{|c|c|c|c|}
\hline Characteristics & & $\begin{array}{l}\text { No./median } \\
\text { (range) }\end{array}$ & $\begin{array}{l}\text { Proportion } \\
(\%)\end{array}$ \\
\hline 3.5 & & 9 & 5.6 \\
\hline 4.0 & & 1 & 0.6 \\
\hline \multicolumn{4}{|l|}{ RPA classification } \\
\hline I & & 50 & 31.1 \\
\hline$\|$ & & 92 & 57.1 \\
\hline III & & 19 & 11.8 \\
\hline \multicolumn{4}{|c|}{$\begin{array}{l}\text { *System therapy cancer: together with chemotherapy or targeted therapy. } \\
\text { KPS, Karnofsky performance status; BM, brain metastases; GPA, graded prognostic } \\
\text { assessment; RPA, recursive partitioning analysis; SRT, stereotactic radiation therapy; } \\
\text { WBRT, whole-brain radiotherapy. }\end{array}$} \\
\hline \multicolumn{4}{|c|}{ TABLE 2 | Pre-SRT clinical symptoms and Post-SRT functional outcomes. } \\
\hline Pre-SRT symptoms & $n$ & Post- SRT & $n$ \\
\hline Headache & 40 & Improved & 33 \\
\hline Dizziness & 32 & Improved & 26 \\
\hline Weakness & 2 & Improved & 2 \\
\hline Dysarthria & 11 & Improved & 6 \\
\hline Vomitting & 18 & Improved & 18 \\
\hline Visual dysfunction & 11 & Improved & 10 \\
\hline Epilepsy & 3 & Improved & 1 \\
\hline Central ataxia & 14 & Improved & 12 \\
\hline Cognitive dysfunction & 4 & Improved & 2 \\
\hline Motor weakness & 38 & Improved & 35 \\
\hline Hemiplegia & 10 & Improved & 8 \\
\hline Hyperspasmia & 7 & Improved & 5 \\
\hline Asymptomatic & 63 & New developed & 15 \\
\hline
\end{tabular}

SRT, stereotactic radiation therapy.

\section{RADIATION TREATMENT TECHNIQUE}

WBRT treatments were administered with 21EX Linear Accelerator (Varian Medical Systems, Palo Alto, CA) using 3D-CRT. SRT were delivered with CyberKnife robotic radiosurgery system (Accuray, Sunnyvale, USA) Metastases were diagnosed based on contrast enhancement MRI imaging. The contours were delineated and reviewed by attending radiation oncologists. Gross tumor volume (GTV) was defined as the area of contrast enhancement on T1-weighted MRI images. The dose was prescribed to a 75\% (at least) isodose. The precise prescription varied with tumor volume, site, and neurologic symptoms.

\section{PATIENTS' FOLLOW UP}

Patients were followed up at regular intervals (every 3 month within 1 year, every 6 month 1 year later) to determine tumor status and the presence of symptoms. All data (clinical, radiological, therapeutic options and response to treatment) were collected by two physicians and the
TABLE 3 | Numbers of patients with 1-5 toxicities.

\begin{tabular}{|c|c|c|}
\hline Grade & Symptom & $n$ \\
\hline \multirow[t]{4}{*}{1} & Headache & 15 \\
\hline & Dizziness & 9 \\
\hline & Weakness & 4 \\
\hline & Seizure & 2 \\
\hline \multirow[t]{3}{*}{2} & Edema & 15 \\
\hline & Hemorrhage & 2 \\
\hline & Seizure & 2 \\
\hline \multirow[t]{2}{*}{3} & Edema & 9 \\
\hline & Hemorrhage & 2 \\
\hline \multirow[t]{3}{*}{4} & Edema & 3 \\
\hline & Hemorrhage & 1 \\
\hline & Cerebral necrosis & 2 \\
\hline \multirow[t]{2}{*}{5} & Hemorrhage & 1 \\
\hline & Cerebral necrosis & 2 \\
\hline Total & & 69 \\
\hline
\end{tabular}

accuracy of the data were confirmed by two administrators. Toxicities were scored according to the Common Toxicity Criteria Adverse Events version 4 (CTCAE v.4). Acute toxicity was defined within 3 months following treatment. Toxicities were graded per RTOG acute central nervous system (CNS) morbidity scoring criteria. Acute toxicity outcomes included patient reported fatigue, headache, nausea/vomiting, dizziness/imbalance, motor neuropathy, sensory neuropathy, edema, neurocognitive dysfunction, and seizures.

\section{FORMULAS AND STATISTICS}

The biological effective dose (BED) was calculated for every metastasis treated according to the following formula, where $\mathrm{n}$ is the number of fractions and $\mathrm{d}$ is the dose per fraction. Following the Linear quadratic model, a value of 10 was used for the $\alpha / \beta$-ratio. $\operatorname{BED}=\mathrm{nd}^{*}[1+\mathrm{d} /(\alpha / \beta)]$. OS started with the first day of irradiation and was estimated using Kaplan-Meier analysis. Subgroups were compared using the log-rank test for univariate analysis and the Cox proportional hazard model for multivariable analysis. A $p<0.05$ was considered statistically significant. A $p<0.1$ was considered a trend and was the criterion for inclusion in multivariable analysis. All statistical analyses were performed using IBM SPSS Statistics 19 (New York, USA).

Patient characteristics were presented with descriptive statistics. Overall survival (OS) curves were calculated by the Kaplan-Meier method. Median OS and 95\% confidence intervals (CIs) were reported. To identify potential predictive factors of OS, a univariate analysis was done with Cox proportional hazards regression within the training cohort. Factors with a $p<0.05$ in the univariate analysis were entered as candidate variables into a multivariate stepwise Cox regression model (conditional backward selection). 


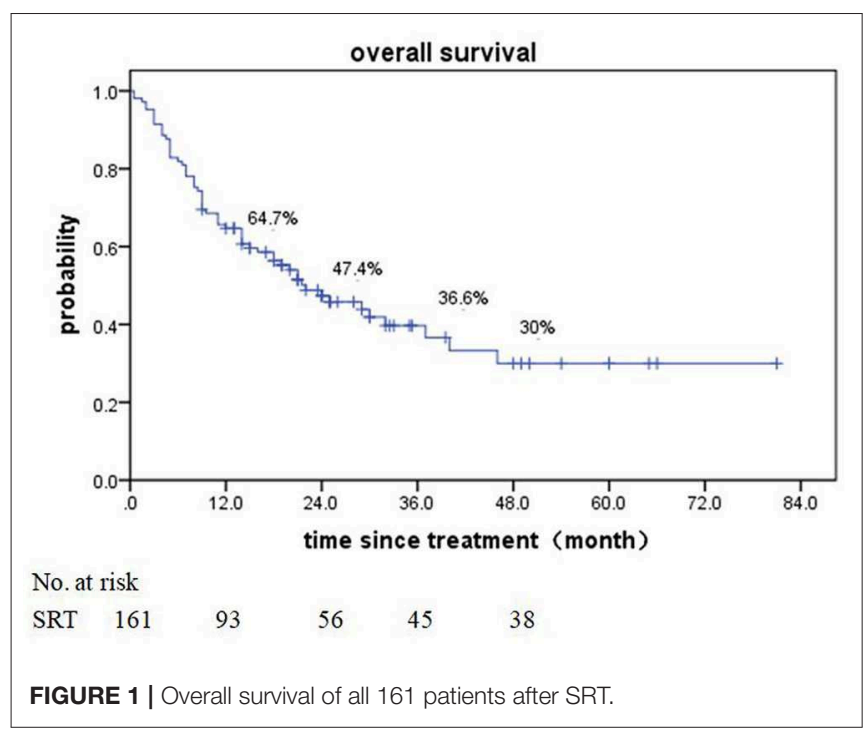

\section{RESULTS}

\section{Patient Clinical and Treatment Characteristics (Table 1)}

One Hundred and sixty-one patients with 305 brain metastases treated with SRT between February 2012 and June 2017 were enrolled in the study. The number of lesions ranged from 1 to 7 (median number of metastases was one). Most Patients $(88.2 \%)$ had the KPS of 70 or higher. The majority of the patients were male $(64 \%)$ and the median age was 61 years (range, 3387). $32.9 \%$ patients showed synchronous brain metastases. $56.5 \%$ patients showed extracranial metastases. Ninety-three patients (57.8\%) had systemic therapies including chemotherapy or targeted therapy. The patients demonstrated a range of primary malignancies, including non-small-cell lung cancer (NSCLC) (65.2\%), gastrointestinal cancer (11.8\%), small-cell lung cancer (SCLC) (6.8\%), breast cancer (4.3\%), renal cell carcinoma (1.9\%), and others (10\%). Most patients had oligometastases (87.6\%) (13). $61.5 \%$ metastases were treated with SRT and $38.5 \%$ were treated with SRT + WBRT. The concurrent WBRT was defined according to Hunter et al. (14) as WBRT was completed within 1 month before or after SRT. In our study, $90 \%$ patients received concurrent WBRT and 10\% patients received WBRT pre or post SRT.

Patients treated with a median dose of 27Gy (20-40 Gy) were with 5-6 fractions. Ninety-one of ninety-nine patients who had neurological symptoms showed remission after SRT. Fortynine $(30 \%)$ patients suffered grade 1-2 toxicities with headache, dizziness, weakness, seizure, or edema. Four (2.5\%) patients had serious cerebral necrosis and needed long-time treatment of bevacizumab (Tables 2, 3).

\section{Overall Survival}

Of patients alive at last follow-up, the median follow-up was 48.5 months. The median overall survival (OS) after SRT was 19 months (range, 0.5-81 month) (Figure 1). The median BED
TABLE 4 | Univariate analysis of predictors associated with OS

\begin{tabular}{|c|c|c|c|}
\hline Variable & HR & $95 \% \mathrm{Cl}$ & $p$-value* \\
\hline Age ( $\leq 61$ vs. $>61$ ) & 1.173 & $0.794-1.733$ & 0.424 \\
\hline Gender (Male vs. Female) & 1.481 & $0.977-2.246$ & 0.064 \\
\hline Tumor volume (> $8.79 \mathrm{cc}$ vs. $\leq 8.79 \mathrm{cc}$ ) & 1.332 & $0.855-2.074$ & 0.296 \\
\hline KPS score (>70 vs. $\leq 70)$ & 0.678 & $0.454-1.011$ & 0.057 \\
\hline Synchronous BM (No vs. Yes) & 0.811 & $0.538-1.224$ & 0.319 \\
\hline Extracranial metastases (Yes vs. No) & 1.640 & $1.096-2.453$ & 0.016 \\
\hline $\mathrm{BED}_{10}(\geq 50$ vs. $<50)$ & 0.547 & $0.299-0.999$ & 0.049 \\
\hline \multicolumn{4}{|l|}{ Number of metastases } \\
\hline Single vs. multiple & 0.569 & $0.384-0.841$ & 0.005 \\
\hline $1-3$ vs. $>3$ & 0.351 & $0.208-0.592$ & $<0.001$ \\
\hline GPA score ( $\geq 2.5 v s . \leq 2)$ & 0.522 & $0.340-0.801$ & 0.003 \\
\hline \multicolumn{4}{|l|}{ RPA classification } \\
\hline Class I vs. II & 0.592 & $0.373-0.940$ & 0.026 \\
\hline Class I vs. III & 0.729 & $0.367-1.450$ & 0.368 \\
\hline Class II vs. III & 1.208 & $0.650-2.245$ & 0.549 \\
\hline $\begin{array}{l}\text { Extracranial disease (Uncontrolled vs. } \\
\text { Controlled) }\end{array}$ & 1.672 & $1.127-2.481$ & 0.011 \\
\hline Symptoms (YES vs. NO) & 1.168 & $0.780-1.750$ & 0.451 \\
\hline Treatment (SRT vs. SRT+WBRT) & 0.930 & $0.627-1.380$ & 0.717 \\
\hline Targeted therapy (YES vs. NO) & 0.162 & $0.102-0.257$ & $<0.001$ \\
\hline Chemotherapy (YES vs. NO) & 0.587 & $0.333-1.034$ & 0.065 \\
\hline Tumor type (NSCLC vs. none NSCLC) & 0.576 & $0.388-0.854$ & 0.006 \\
\hline
\end{tabular}

*Univariable analysis with Cox proportional hazards regression; Cl, confidence interval; Bold values indicate $p<0.05$.

was $39.15 \mathrm{~Gy}$ (range, 16.8-84.375Gy). The median time from diagnosis to brain metastasis was $10 \mathrm{M}$ (range, $0-300$ month). The median total lesion volume was $8.79 \mathrm{cc}$ (range, $0.113-179.31 \mathrm{cc}$ ).

The univariable analyses with Cox proportional hazards regression are shown in Table 4 . The $\mathrm{BED}_{10}-\mathrm{SRT}$ ( $\geq 50$ vs. $<50$, $p=0.05)$, a GPA of 2.5 significantly influenced OS $(P=0.003)$, the number of lesions treated (single lesion vs. multiple lesions, $p=0.005$ and $1-3$ lesions vs. more than 3 lesions, $p<0.001$ ) significantly influenced OS. Targeted therapy also significantly influenced OS (24 months for targeted therapy vs. 13 months for no targeted therapy, $p<0.001)$. Combined with extracranial metastasis significantly influenced OS (13 months for with extracranial metastasis vs. 24 months for without, $p<0.016$ ). Furthermore, controlled of extracranial disease also achieved significance (13.5 months for uncontrolled vs. 24 months for controlled, $p=0.011$ ). RPA class I achieved a median OS of 31.5 months and class II achieved a median OS of 14 months $(p=0.026)$. Primary tumor type significantly also influenced OS (NSCLC achieved a median OS of 22 months and non-NSCLC achieved a median OS of 11 months, $P=0.005$ ).

SRT only, compared with concurrent WBRT, had no statistical significance $(p=0.717)$. There is no statistical significance for the time from diagnosis to brain metastasis $(p=0.319)$. Neurological symptoms before treatment had no significant influence $(p=0.451)$. There was a trend toward better survival rates for together with chemotherapy and higher KPS.

Of all 161 patients, multivariable analyses were shown in Table 5. $\mathrm{BED}_{10}-\mathrm{SRT} \geq 50 \mathrm{~Gy}(p=0.027)$, targeted therapy 
TABLE 5 | Multivariate analysis of predictors associated with OS.

\begin{tabular}{|c|c|c|}
\hline Variable & HR (95\%Cl) & $P$-value* \\
\hline \multicolumn{3}{|c|}{ Extracranial metastases } \\
\hline YES & NA & 0.509 \\
\hline NO & NA & \\
\hline \multicolumn{3}{|l|}{$\mathrm{BED}_{10}$} \\
\hline$\geq 50 G y$ & $0.504(0.275-0.924)$ & 0.027 \\
\hline$<50 G y$ & 1 (ref) & \\
\hline \multicolumn{3}{|c|}{ Number of metastases (1-3 vs. >3) } \\
\hline (1) Single & NA & 0.279 \\
\hline Multiple & NA & \\
\hline (2) $1-3$ & NA & 0.529 \\
\hline$>3$ & NA & \\
\hline \multicolumn{3}{|l|}{ GPA score } \\
\hline$\geq 2.5$ & NA & 0.883 \\
\hline$\leq 2$ & NA & \\
\hline \multicolumn{3}{|l|}{ Extracrinal disease } \\
\hline Uncontrolled & 1 (ref) & 0.039 \\
\hline Controlled & $0.658(0.442-0.978)$ & \\
\hline \multicolumn{3}{|l|}{ Targeted therapy } \\
\hline YES & $0.157(0.098-0.250)$ & $<0.001$ \\
\hline NO & 1 (ref) & \\
\hline \multicolumn{3}{|l|}{ RPA classification } \\
\hline Class I & NA & 0.628 \\
\hline Class II & NA & \\
\hline \multicolumn{3}{|l|}{ Tumor type } \\
\hline NSCLC & NA & 0.182 \\
\hline None NSCLC & NA & \\
\hline
\end{tabular}

*Multivariate analysis using the Cox proportional hazards model; NA, Not Available; Cl, confidence interval; Bold values indicate $p<0.05$.

$(p<0.001)$ and controlled of extracranial disease $(p=0.039)$ were significant predictive factors (Figures 2-4).

In the meantime, the median OS after SRT was 22 months (range, 0.5-81 month) in NSCLC (Figure 5). The univariable analyses are shown in Table 6. In multivariable analysis, controlled of extracranial disease $(p=0.012)$ and targeted therapy (EGFR-TKI) $(p<0.001)$ were associated with improved OS (Table 7; Figures 6, 7).

\section{DISCUSSION}

In our study, we collected data of 161 eligible patients with BM in this study. The results showed that higher $\mathrm{BED}_{10}-\mathrm{SRT}$, controlled of extracranial disease and targeted therapy were significant predictive factors.

WBRT is the common approach to the treatment for the patients with BM historically. Compared with WBRT, SRT alone or in combination with other modalities is generally used as the standard option for patients with BM especially oligometastasis, which leads to more clinical benefit and less toxicity.

For multiple brain metastases, WBRT was a standard choice for most cases over a long period of time. But the neurocognitive
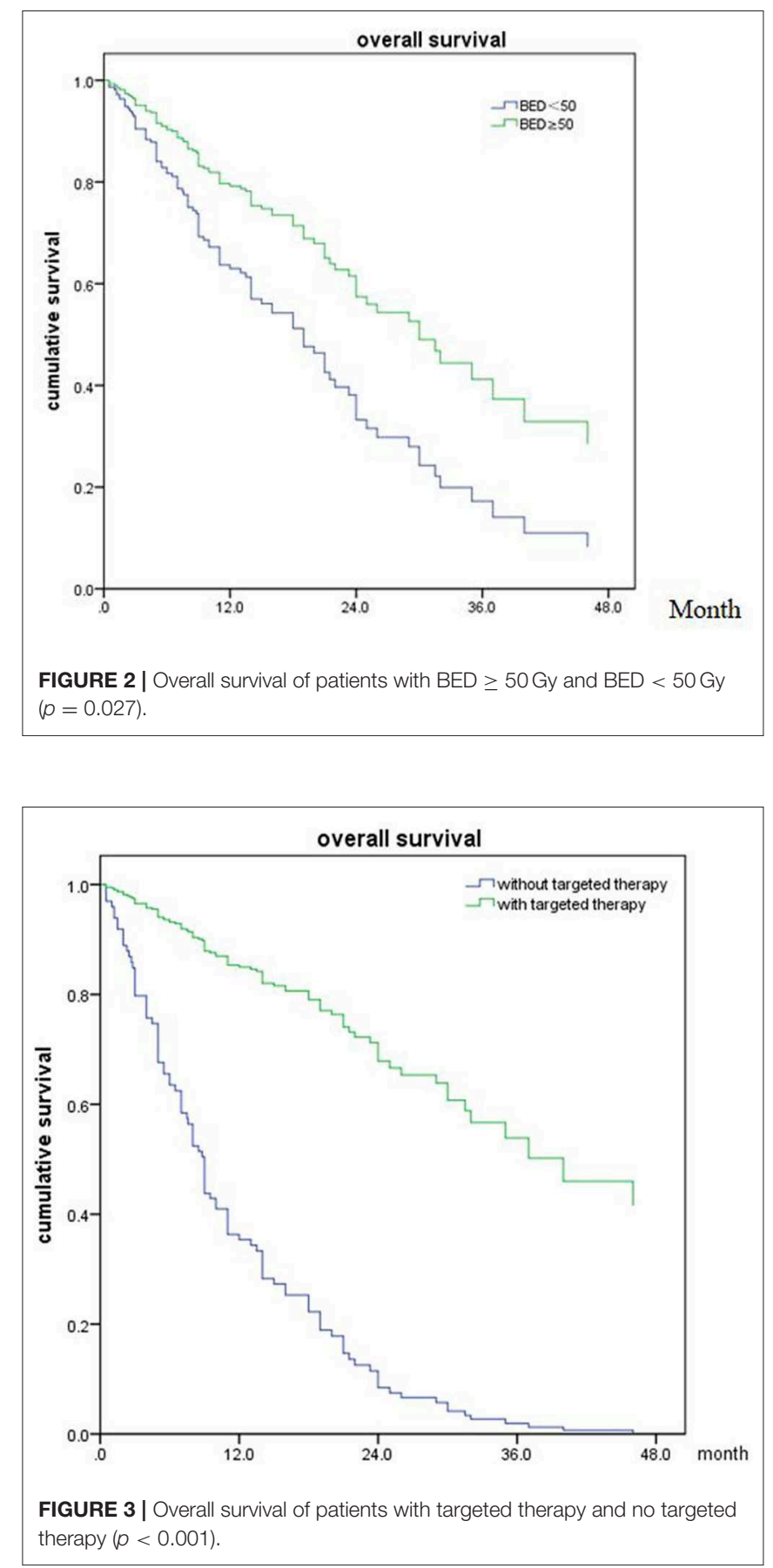

dysfunction cannot be ignored in longtime survival patients. Therefore, SRT has been more and more commonly used recently. Recent studies have shown that local treatments may minimize long-term neurocognitive dysfunction and improve quality of life (QOL) without compromising OS (15). Contrarily, Brown et al. (16) demonstrates that SRT alone may be associated with improved neurocognitive effects and quality of life despite the increased intracranial relapse rate. However, there have been no definitive conclusions whether treatment with SRT is as 

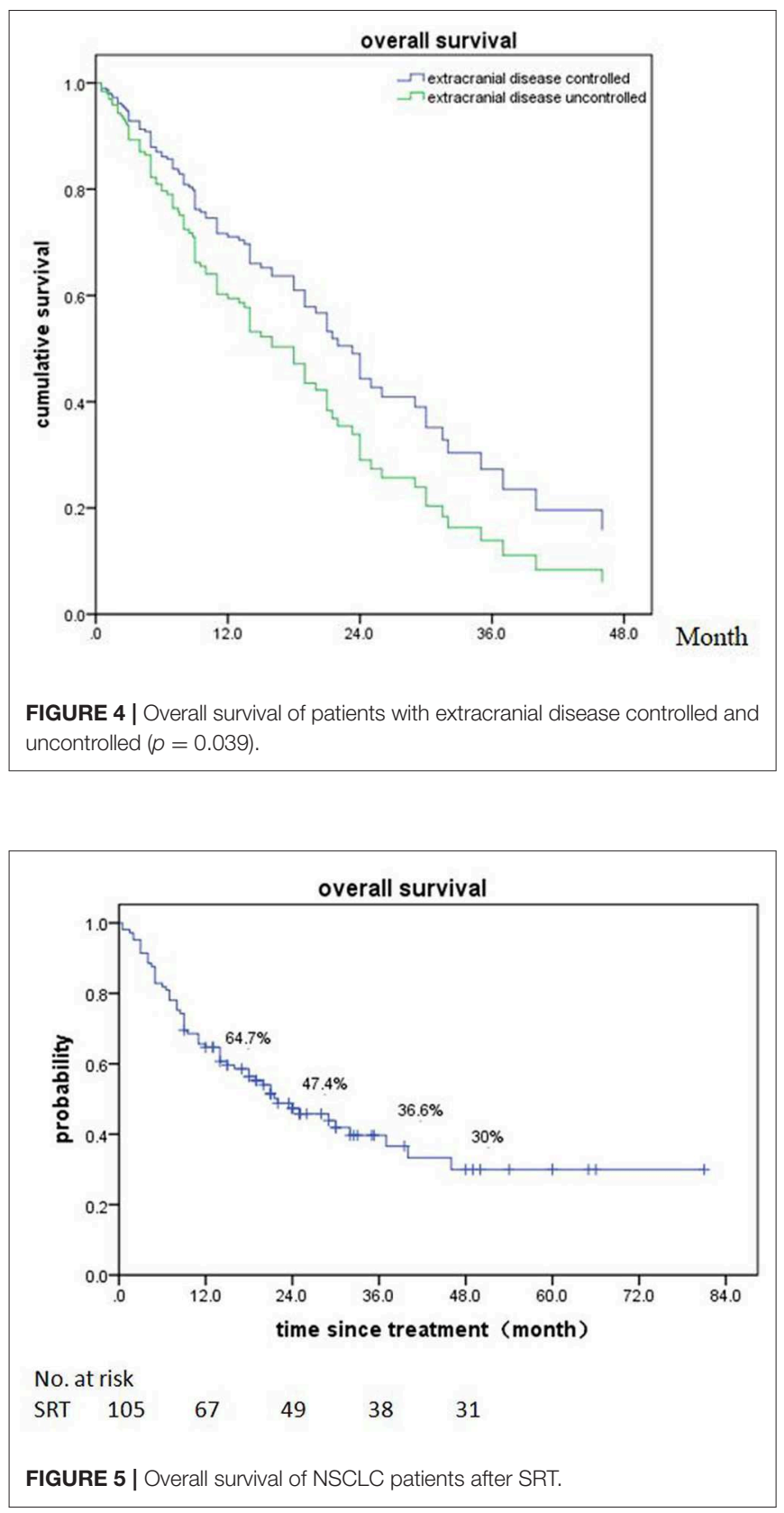

effective as that with WBRT or WBRT plus SRT in some specific number of brain metastases.

The prognostic factors related to better OS for patients with brain metastases have been studied in a large amount of clinical trials. Many prognostic scoring systems (17) have been proposed in the last 30 years to define the prognosis and better therapeutic option.

Study series showed that the factors of RPA class, GPA score, KPS, primary tumor category, extracranial diseases status, and number of brain lesions were variables associated with overall survival post-SRT $(18,19)$. A smaller trial (20) showed that combined WBRT and radiosurgery for patients with two to four
TABLE 6 | Univariate analysis of predictors associated with OS in NSCLC.

\begin{tabular}{|c|c|c|c|}
\hline Variable & HR & $95 \% \mathrm{Cl}$ & $p$-value* \\
\hline Age ( $\leq 61$ vs. $>61)$ & 1.193 & $0.794-1.733$ & 0.502 \\
\hline Gender (Male vs. Female) & 2.275 & $0.977-2.246$ & 0.009 \\
\hline Tumor volume ( $\leq 8.79 \mathrm{cc}$ vs. $>8.79 \mathrm{cc}$ ) & 1.332 & $0.855-2.074$ & 0.296 \\
\hline KPS score (>70 vs. $\leq 70)$ & 0.674 & $0.401-1.135$ & 0.138 \\
\hline Synchronous BM (No vs. Yes) & 0.729 & $0.435-1.222$ & 0.231 \\
\hline Extracranial metastases (Yes vs. No) & 1.603 & $0.956-2.689$ & 0.074 \\
\hline $\mathrm{BED}_{10}(\geq 50$ vs. $<50)$ & 0.547 & $0.299-0.999$ & 0.090 \\
\hline \multicolumn{4}{|l|}{ Number of metastases (1-3 vs. >3) } \\
\hline Single vs. multiple & 0.665 & $0.397-1.113$ & 0.121 \\
\hline $1-3$ vs. $>3$ & 0.386 & $0.165-0.908$ & 0.029 \\
\hline GPA score ( $\geq 2.5$ vs. $\leq 2)$ & 0.628 & $0.370-1.067$ & 0.085 \\
\hline \multicolumn{4}{|l|}{ RPA classification } \\
\hline Class I vs. || & 0.543 & $0.289-1.020$ & 0.057 \\
\hline Class I vs. III & 0.729 & $0.367-1.450$ & 0.368 \\
\hline Class II vs. III & 1.208 & $0.650-2.245$ & 0.549 \\
\hline $\begin{array}{l}\text { Extracranial disease (Uncontrolled vs. } \\
\text { Controlled) }\end{array}$ & 2.096 & $1.244-3.532$ & 0.005 \\
\hline Symptoms (Yes vs. No) & 1.214 & $0.723-2.039$ & 0.463 \\
\hline Treatment (SRT vs. SRT+WBRT) & 1.204 & $0.721-2.009$ & 0.473 \\
\hline Targeted therapy (YES vs. NO) & 0.161 & $0.088-0.294$ & $<0.001$ \\
\hline Chemotherapy (YES vs. NO) & 0.587 & $0.333-1.034$ & 0.083 \\
\hline
\end{tabular}

*Univariable analysis with Cox proportional hazards regression; Cl, confidence interval; Bold values indicate $p<0.05$.

TABLE 7 | Multivariate analysis of predictors associated with OS in NSCLC.

\begin{tabular}{|c|c|c|}
\hline Variable & HR $(95 \% \mathrm{Cl})$ & $P$-value* \\
\hline \multicolumn{3}{|c|}{ Number of metastases ( $1-3$ vs. $>3$ ) } \\
\hline $1-3$ & NA & 0.513 \\
\hline$>3$ & NA & \\
\hline \multicolumn{3}{|l|}{ Gender } \\
\hline Male & NA & 0.378 \\
\hline Female & NA & \\
\hline \multicolumn{3}{|c|}{ Extracranial disease } \\
\hline Uncontrolled & 1 (ref) & 0.012 \\
\hline Controlled & $0.512(0.303-0.865)$ & \\
\hline \multicolumn{3}{|l|}{ Targeted therapy } \\
\hline YES & $0.168(0.092-0.307)$ & $<0.001$ \\
\hline NO & 1 (ref) & \\
\hline
\end{tabular}

*Multivariate analysis using the Cox proportional hazards model; NA, Not Available; Cl, confidence interval. Bold values indicate $p<0.05$.

brain metastases significantly improves local control of brain disease, but no improvement of survival.

Besides intracranial tumor burden, other clinical factors play an important role in treatment decisions. Performance status, age, extracranial metastases, and primary tumor control are all present in the GPA classification (21). As small samples and the paucity of data for SRT treating brain metastases, we analyzed the outcomes of patients with brain metastases treated with SRT with or without other treatments in different primary cancers. 


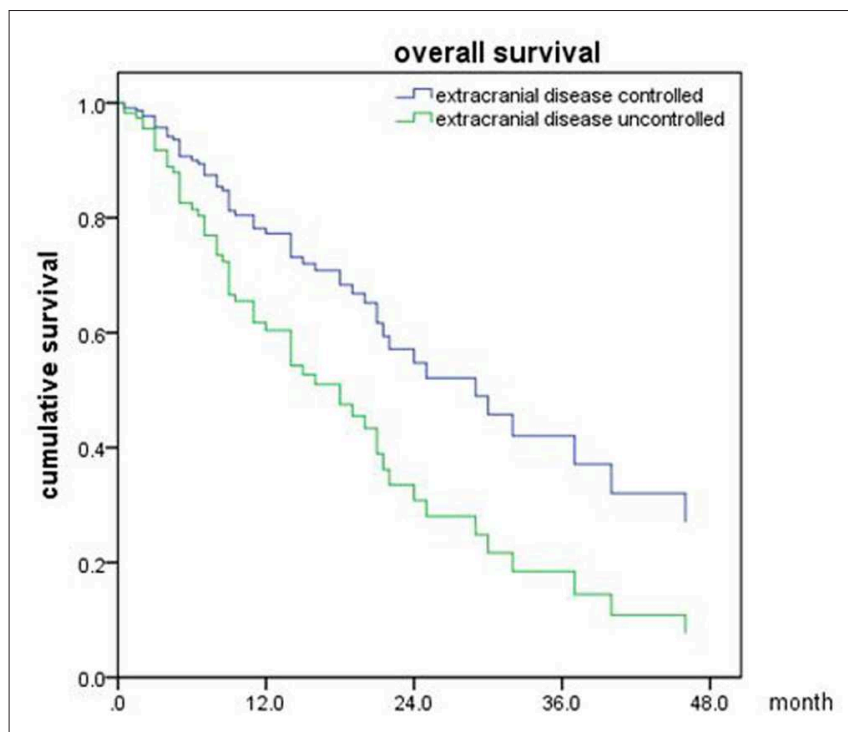

FIGURE 6 | Overall survival of NSCLC patients with extracranial disease controlled and uncontrolled ( $p=0.012$ ).

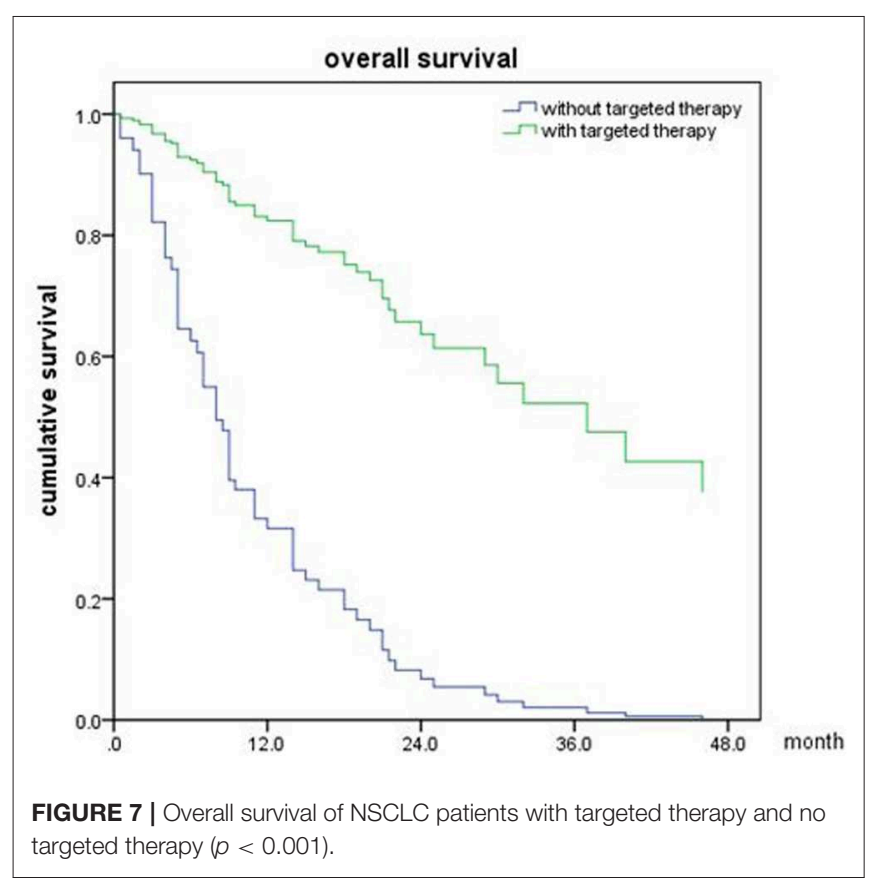

Similarly, our study also explored extracranial diseases status (controlled vs. not controlled) were variables predicting OS. But we didn't find the relationship between OS and RPA, GPA, KPS score as well as the number of brain lesions. Possibly because patients who received SRT had better KPS and less neurological symptoms before treatment.

The most common primary cancers that metastasize to the brain are lung cancer, renal cancer, melanoma, colorectal cancer, and breast cancer. About $6 \%$ of those patients, brain metastases occur within 1 year of the diagnosis of the primary cancer (22). The failure of medical therapies in BM was well-known due to the lack of blood brain barrier (BBB) penetration. Fortunately the molecular targeted therapies have shown efficacy in the management of BM patients with activating mutations. Moreover, the target therapy was observed as a prognostic factor in BM patients, which can be effective for both intracranial as well as extracranial disease post-SRT.SRT alone had been widely accepted for treatment of oligo-brain metastases (1-4 brain metastases) In previous studies, the role of radiosurgery alone for patients with multiple brain metastases is still controversial. WBRT has classically been the standard treatment, while radiosurgery is commonly considered as a salvage therapy $(23,24)$.

Although the addition of WBRT improves intracranial control, it induces an increased risk of cognitive impairment without benefit in OS in the population of patients with brain metastasis, including patients with NSCLC (25-27).

A multi-institutional prospective observational study enrolled 1,194 patients with 1-10 brain metastases with an accumulated volume of all metastases $<15 \mathrm{ml}$, treated with radiosurgery, showed that overall survival and toxicity did not differ between those with the 2-4 and 5-10 metastases groups $(p=0.78$ median overall survival, 10.8 vs. 10.8 months, respectively) (28), which suggests that SRT-alone may be a reasonable treatment for patients with multiple brain metastases. The same result was also obtained in our study, WBRT was not independently associated with improved OS, no matter the primary tumor category or the number of brain lesions. However, the prospective randomized clinical trials are needed to evaluate the role of radiosurgery alone with omission of upfront WBRT in patients with multiple BM.

In the meanwhile, $\mathrm{BED}_{10}$ as an independent prognostic factor with OS was rarely reported before. In our study, an average prescription dose of 27Gy (20-40Gy) in 5-6 fractions was schemed, which was believed to be safe and effective dose for BM (29). Kumar et al. (30) reported that a higher total $\mathrm{BED}_{10}$ was statistically significant for improved local control $(p=0.04)$ with a threshold $\mathrm{BED}_{10} \geq 48 \mathrm{~Gy}$ associated with better local control for $B M$ patients after surgical resection. We observed that $B E D_{10} \geq 50 \mathrm{~Gy}$ was associated with overall survival in the whole population of patients with BM, but not in BM from NSCLC. Previously the medical treatment was limited in BM patient because of blood-brain barrier. In the last decade, the targeted therapies of TKI had contributed to local control with concurrent radiotherapy for most NSCLC with activating mutations. Based on our data, we would recommend a higher $\mathrm{BED}_{10}$ for the patients lack of effective target drug or with relative radiation resistance primary tumor.

Some studies have reported nearly $10 \%$ of new NSCLC patients have brain metastases at diagnosis (31) and a further $25-40 \%$ patients will develop brain metastases during the course of disease (32). The NSCLC patients with EGFR mutation have a higher diagnosis rate of BM. The median OS is $\sim 3-6$ months or even less for patients without treatment $(5,33)$. A retrospective study showed SRT achieved better OS than WBRT or EGFR TKI alone (46 vs. 30 vs. $25 \mathrm{~m}$ respectively) in NSCLC patients with EGFR mutated (34).So cranial radiotherapy plays a critical role in 
patients with BM in NSCLC. In our research, we also find that EGFR-TKI $(p<0.001)$ and controlled of extracranial diseases $(p=0.012)$ were associated with improved OS in NSCLC patients.

Numerous studies have demonstrated that radiotherapy plus EGFR-TKIs led to more promising results than EGFR-TKIs or radiotherapy alone (35). SRT might be an optimal treatment for patients with EGFR mutations rather than WBRT. Thus, extracranial disease control is of the highly relevant with the OS of BM patients.

There are also some limitations in this study. Firstly, this is a retrospective study in a single institution, which included unrecognized biases and confounding factors. Secondly we could not collect much more details about the progression of the BM lesions during the long interval time of the follow-up, which caused the unmeasured intracranial PFS.

\section{CONCLUSION}

As the development of radiotherapy, SRT adoption has dramatically improved the treatment outcomes compared with conventional fractionated radiotherapy for the BM patients. There was no difference in overall survival that has been observed between SRT alone compared to SRT plus WBRT in limited number of BM patients. The concurrent WBRT with SRT should be a cautious choice for selected patients. Our study confirmed that excellent extracranial disease controlled

\section{REFERENCES}

1. Frisk G, Svensson T, Backlund LM, Lidbrink E, Blomqvist P, Smedby KE. Incidence and time trends of brain metastases admissions among breast cancer patients in Sweden. Br J Cancer. (2012) 106:1850-3. doi: 10.1038/bjc.2012.163

2. Goncalves PH, Peterson SL, Vigneau FD, Shore RD, Quarshie WO, Islam $\mathrm{K}$, et al. Risk of brain metastases in patients with nonmetastatic lung cancer: Analysis of the Metropolitan Detroit Surveillance, Epidemiology, and End Results (SEER) data. Cancer. (2016) 122:1921-7. doi: 10.1002/cncr. 30000

3. Arita H, Narita Y, Miyakita Y, Ohno M, Sumi M, Shibui S. Risk factors for early death after surgery in patients with brain metastases: reevaluation of the indications for and role of surgery. J Neurooncol. (2014) 116:14552. doi: 10.1007/s11060-013-1273-5

4. Barnholtz-Sloan JS, Sloan AE, Davis FG, Vigneau FD, Lai P, Sawaya RE. Incidence proportions of brain metastases in patients diagnosed (1973 to 2001) in the Metropolitan Detroit Cancer Surveillance System. J Clin Oncol. (2004) 22:2865-72. doi: 10.1200/JCO.2004.12.149

5. Shin DY, Na II, Kim CH, Park S, Baek H, Yang SH. EGFR mutation and brain metastasis in pulmonary adenocarcinomas. J Thorac Oncol. (2014) 9:195-9. doi: 10.1097/JTO.0000000000000069

6. Eichler AF, Chung E, Kodack DP, Loeffler JS, Fukumura D, Jain RK. The biology of brain metastases-translation to new therapies. Nat Rev Clin Oncol. (2011) 8:344-56. doi: 10.1038/nrclinonc.2011.58

7. Fink KR, Fink JR. Imaging of brain metastases. Surg Neurol Int. (2013) 4 (Suppl. 4):S209-19. doi: 10.4103/2152-7806.111298

8. Mintz AH, Kestle J, Rathbone MP, Gaspar L, Hugenholtz H, Fisher B, et al. A randomized trial to assess the efficacy of surgery in addition to radiotherapy in patients with a single cerebral metastasis. Cancer. (1996) 78:1470-6.3.0.

9. Patchell RA, Tibbs PA, Walsh JW, Dempsey RJ, Maruyama $\mathrm{Y}$, Kryscio RJ, et al. A randomized trial of surgery in the and $\mathrm{BED}_{10}-\mathrm{SRT} \geq 50 \mathrm{~Gy}$ may predict a favorable prognosis in $\mathrm{BM}$ patients treated with SRT.

\section{DATA AVAILABILITY STATEMENT}

All datasets generated for this study are included in the article/supplementary material.

\section{AUTHOR CONTRIBUTIONS}

LG and SQ have made equal contribution to the study and provided the largest writing contribution of the manuscript. $\mathrm{HZ}$ was the main principal of this study. $\mathrm{XZ}$, $\mathrm{XJ}, \mathrm{YC}, \mathrm{ZJ}, \mathrm{YS}, \mathrm{FC}$, and FF have performed collection and organization of data. All authors approved it for publication.

\section{FUNDING}

This study was sponsored by National Key Research and Development Projects (2017YFC0113104).

\section{ACKNOWLEDGMENTS}

We are grateful for Dr. Jiuhong Chen responsible for constructive comments and precise revisions and LinkDoc for their advice of patients' follow-up.

treatment of single metastases to the brain. $N$ Engl J Med. (1990) 322:494-500. doi: 10.1056/NEJM199002223220802

10. Vecht CJ, Haaxma-Reiche H, Noordijk EM, Padberg GW, Voormolen JH, Hoekstra FH, et al. Treatment of single brain metastasis: radiotherapy alone or combined with neurosurgery? Ann Neurol. (1993) 33:58390. doi: 10.1002/ana.410330605

11. Andrews DW, Scott CB, Sperduto PW, Flanders AE, Gaspar LE, Schell $\mathrm{MC}$, et al. Whole brain radiation therapy with or without stereotactic radiosurgery boost for patients with one to three brain metastases: phase III results of the RTOG 9508 randomised trial. Lancet. (2004) 363:166572. doi: 10.1016/S0140-6736(04)16250-8

12. Sperduto PW, Shanley R, Luo X, Andrews D, Werner-Wasik M, Valicenti $\mathrm{R}$, et al. Secondary analysis of RTOG 9508, a phase 3 randomized trial of whole-brain radiation therapy versus WBRT plus stereotactic radiosurgery in patients with 1-3 brain metastases; poststratified by the graded prognostic assessment (GPA). Int J Radiat Oncol Biol Phys. (2014) 90:526-31. doi: 10.1016/j.ijrobp.2014.07.002

13. Nogi S, Nakayama H, Tajima Y, Okubo M, Mikami R, Kanesaka N, et al. Significance of the number of brain metastases for identifying patients who don't need whole brain radiotherapy: implication as oligometastases of the brain. J Radiosurg SBRT. (2013) 2:119-26.

14. Hunter GK, Suh JH, Reuther AM, Vogelbaum MA, Barnett GH, Angelov L, et al. Treatment of five or more brain metastases with stereotactic radiosurgery. Int J Radiat Oncol Biol Phys. (2012) 83:13948. doi: 10.1016/j.ijrobp.2011.10.026

15. Tsao $\mathrm{M}, \mathrm{Xu} \mathrm{W}$, Sahgal A. A meta-analysis evaluating stereotactic radiosurgery, whole-brain radiotherapy, or both for patients presenting with a limited number of brain metastases. Cancer. (2012) 118:248693. doi: $10.1002 / \mathrm{cncr} .26515$

16. Brown PD, Jaeckle K, Ballman KV, Farace E, Cerhan JH, Anderson SK, et al. Effect of radiosurgery alone vs radiosurgery with whole brain radiation therapy on cognitive function in patients with 1 to 3 
Brain metastases: a randomized clinical trial. JAMA. (2016) 316:401409. doi: 10.1001/jama.2016.9839

17. Zindler JD, Rodrigues G, Haasbeek CJ, De Haan PF, Meijer OW, Slotman BJ, et al. The clinical utility of prognostic scoring systems in patients with brain metastases treated with radiosurgery. Radiother Oncol. (2013) 106:3704. doi: 10.1016/j.radonc.2013.01.015

18. Sperduto PW, Berkey B, Gaspar LE, Mehta M, Curran W. A new prognostic index and comparison to three other indices for patients with brain metastases: an analysis of 1,960 patients in the RTOG database. Int J Radiat Oncol Biol Phys. (2008) 70:510-4. doi: 10.1016/j.ijrobp.2007.06.074

19. Cho KH, Hall WA, Gerbi BJ, Higgins PD, Bohen M, Clark HB. Patient selection criteria for the treatment of brain metastases with stereotactic radiosurgery. J Neurooncol. (1998) 40:73-86. doi: 10.1023/A:1006169109920

20. Kondziolka D, Patel A, Lunsford LD, Kassam A, Flickinger JC. Stereotactic radiosurgery plus whole brain radiotherapy versus radiotherapy alone for patients with multiple brain metastases. Int J Radiat Oncol Biol Phys. (1999) 45:427-34. doi: 10.1016/S0360-3016(99)00198-4

21. Sperduto PW, Chao ST, Sneed PK, Luo X, Suh J, Roberge D, et al. Diagnosis-specific prognostic factors, indexes, and treatment outcomes for patients with newly diagnosed brain metastases: a multi-institutional analysis of 4,259 patients. Int J Radiat Oncol Biol Phys. (2010) 77:65561. doi: 10.1016/j.ijrobp.2009.08.025

22. Gavrilovic IT, Posner JB. Brain metastases: epidemiology and pathophysiology. $J$ Neurooncol. (2005) 75:514. doi: 10.1007/s11060-004-8093-6

23. Brown PD, Brown CA, Pollock BE, Gorman DA, Foote RL. Stereotactic radiosurgery for patients with "radioresistant" brain metastases. Neurosurgery. (2002) 51:656-65; discussion 665-7. doi: 10.1227/00006123-200209000-00009

24. Orgogozo JM, Rigaud AS, Stoffler A, Mobius HJ, Forette F. Efficacy and safety of memantine in patients with mild to moderate vascular dementia: a randomized, placebo-controlled trial (MMM 300). Stroke. (2002) 33:18349. doi: 10.1161/01.STR.0000020094.08790.49

25. Chang EL, Wefel JS, Hess KR, Allen PK, Lang FF, Kornguth DG, et al. Neurocognition in patients with brain metastases treated with radiosurgery or radiosurgery plus whole-brain irradiation: a randomised controlled trial. Lancet Oncol. (2009) 10:1037-44. doi: 10.1016/S1470-2045(09)70263-3

26. Aoyama H, Tago M, Kato N, Toyoda T, Kenjyo M, Hirota S, et al. Neurocognitive function of patients with brain metastasis who received either whole brain radiotherapy plus stereotactic radiosurgery or radiosurgery alone. Int J Radiat Oncol Biol Phys. (2007) 68:1388-95. doi: 10.1016/j.ijrobp.2007.03.048
27. Trifiletti DM, Larner JM, Sheehan JP. When should patients with brain metastases receive whole brain irradiation? J Radiosurg SBRT. (2016) 4:1-3.

28. Yamamoto M, Serizawa T, Shuto T, Akabane A, Higuchi Y, Kawagishi J, et al. Stereotactic radiosurgery for patients with multiple brain metastases (JLGK0901): a multi-institutional prospective observational study. Lancet Oncol. (2014) 15:387-95. doi: 10.1016/S1470-2045(14)70061-0

29. Lischalk JW, Oermann E, Collins SP, Nair MN, Nayar VV, Bhasin R, et al. Five-fraction stereotactic radiosurgery (SRS) for single inoperable high-risk non-small cell lung cancer (NSCLC) brain metastases. Radiat Oncol. (2015) 10:216. doi: 10.1186/s13014-015-0525-2

30. Kumar AMS, Miller J, Hoffer SA, Mansur DB, Coffey M, Lo SS, et al. Postoperative hypofractionated stereotactic brain radiation (HSRT) for resected brain metastases: improved local control with higher BED10. J Neurooncol. (2018) 139:449-54. doi: 10.1007/s11060-018-2885-6

31. Schuette W. Treatment of brain metastases from lung cancer: chemotherapy. Lung Cancer. (2004) 45 (Suppl. 2):S253-7. doi: 10.1016/j.lungcan.2004.07.967

32. Dempke WC, Edvardsen K, Lu S, Reinmuth N, Reck M, Inoue A. Brain metastases in NSCLC - are TKIs changing the treatment strategy? Anticancer Res. (2015) 35:5797-806.

33. Nussbaum ES, Djalilian HR, Cho KH, Hall WA. Brain metastases. Histology, multiplicity, surgery, and survival. Cancer. (1996) 78:1781-8.

34. Magnuson WJ, Lester-Coll NH, Wu AJ, Yang TJ, Lockney NA, Gerber $\mathrm{NK}$, et al. Management of brain metastases in tyrosine kinase inhibitornaive epidermal growth factor receptor-mutant non-small-cell lung cancer: a retrospective multi-institutional analysis. J Clin Oncol. (2017) 35:10707. doi: 10.1200/JCO.2016.69.7144

35. Jiang T, Min W, Li Y, Yue Z, Wu C, Zhou C. Radiotherapy plus EGFR TKIs in non-small cell lung cancer patients with brain metastases: an update meta-analysis. Cancer Med. (2016) 5:1055-65. doi: 10.1002/cam4.673

Conflict of Interest: The authors declare that the research was conducted in the absence of any commercial or financial relationships that could be construed as a potential conflict of interest.

Copyright (C) 2019 Gu, Qing, Zhu, Ju, Cao, Jia, Shen, Cao, Fang and Zhang. This is an open-access article distributed under the terms of the Creative Commons Attribution License (CC BY). The use, distribution or reproduction in other forums is permitted, provided the original author(s) and the copyright owner(s) are credited and that the original publication in this journal is cited, in accordance with accepted academic practice. No use, distribution or reproduction is permitted which does not comply with these terms. 